\title{
UMA DÉCADA DE CONSUMO DE TELEFONIA CELULAR REFLETIDA NA PUBLICIDADE DE UMA MARCA.
}

\section{A decade of mobile telephony consumption reflected in the advertising of a brand.}

\section{Una década de consumo de telefonía móvil reflejada en la publicidad de una marca.}

\author{
Silvio Koiti Sato ${ }^{1}$
}

\section{Resumo}

Neste artigo, refletimos sobre o rápido desenvolvimento da telefonia móvel no Brasil na última década. Ao analisar a publicidade do setor neste período, identificamos como as alterações no cenário competitivo e nos serviços oferecido são refletidos na comunicação das marcas. O roteiro analítico teve como base a Teoria Geral dos Signos de Charles Sanders Peirce e possibilitou identificar diferenças situacionais e evoluções no potencial de significados criados pela publicidade.

Palavras-chave: mobilidade, celular, propaganda, semiótica, branding.

\begin{abstract}
In this article, we reflect on the rapid development of mobile telephony in Brazil in the last decade. By analyzing the advertising of the sector in this period, we identified how changes in the competitive scenario and the services offer are reflected in brand communication. The analytic roadmap was based on the General Theory of Signs of Charles Sanders Peirce and enabled us to identify situational differences and changes in potential meanings created by advertising.
\end{abstract}

Keywords: mobility, cell phone, advertising, semiotics, branding.

\section{Resumen}

En este artículo se reflexiona sobre el rápido desarrollo de la telefonía móvil en Brasil en la última década. Mediante el análisis de la publicidad del sector en este período, se

\footnotetext{
${ }^{1}$ Doutorando e Mestre em Ciências da Comunicação pela ECA-USP. Especialista em Administração de Empresas pela EAESP/FGV-SP. Bacharel em Comunicação Social pela ESPM-SP. Bolsista CAPES. Professor da Faculdade de Comunicação da FAAP. E-mail: silviosato@usp.br.
} 
Uma década de consumo de telefonia celular refletida na publicidade de uma marca de Silvio Koiti Sato

identificaron como los cambios en el panorama competitivo y los servicios que ofrece se reflejan en la comunicación de marca. El guión se basó en la teoría analítica general de los signos de Charles Sanders Peirce y nos ha permitido identificar las diferencias situacionales y los cambios en los significados potenciales generados por la publicidad.

Palabras-clave: movilidad, celular, publicidad, semiótica, branding.

\section{INTRODUÇÃO}

A história da telefonia móvel no Brasil é marcada pelo rápido desenvolvimento do setor, o que provocou inúmeras alterações no cotidiano da população. A popularização do celular no país ocorre a partir de 1997, quando é iniciada a privatização dos serviços de telefonia celular, anteriormente controlados pelo Estado por meio do sistema Telebras. Os leilões e concessões de licença para operações regionais a grupos privados nacionais e internacionais transformaram o setor, que passa a ter uma nova dinâmica, mais competitiva e profissional. Entretanto, é a partir da década de 2000 que a configuração de mercado atual é delineada, com quatro grandes competidores nacionais (Claro, Oi, TIM e Vivo) que trouxeram grandes investimentos em tecnologia, infraestrutura, lançamento de novos aparelhos, funcionalidades e serviços, com agressivas estratégias de marketing e propaganda.

O intenso ritmo de crescimento do setor no Brasil pode ser visto pelos indicadores da última década: se em 2002 havia 34,8 milhões de celulares, em 2012 esse número cresceu para 260 milhões (dados de novembro/2012 - Fonte: Teleco). O país é hoje o quinto maior mercado de telefonia celular no mundo, atrás apenas para China, Índia, EUA e Indonésia (Fonte: Teleco).

$\mathrm{O}$ acirramento da concorrência entre os quatro players nacionais é visível no equilíbrio entre essas marcas em participação de mercado: a Vivo é líder de mercado com $29,22 \%$, a TIM possui $26,74 \%$, a Claro tem $24,75 \%$ e a Oi possui $18,98 \%$ do mercado (dados de novembro/2012 - Fonte: Teleco). O equilíbrio de market share, somado a fatores que diminuíram os obstáculos à saída de clientes - como regras mais rígidas de atendimento ao cliente e a implementação da portabilidade numérica no setor - conduziram o foco de marketing atual das operadoras para a fidelização e a rentabilização da base de clientes. Além disso, as marcas passam a incorporar novos 
Uma década de consumo de telefonia celular refletida na publicidade de uma marca

serviços como pacotes convergentes de serviços de telecomunicações: telefonia fixa e móvel, internet banda larga fixa e móvel, televisão a cabo e longa distância.

Para divulgar e estimular o consumo, as marcas investem cada vez mais em marketing e comunicação. As quatro marcas de telefonia celular figuram no ranking dos maiores anunciantes do Brasil, totalizando um volume de investimento anual superior a R \$2,505 bilhões (Dados de 2011 - Fonte: Ibope Monitor).

\section{SOCIEDADE EM REDE E COMUNICAÇÃO MÓVEL}

A mobilidade proporcionada pela telefonia móvel é objeto de estudo e de discussões pelas modificações que traz para o ambiente contemporâneo, suas relações com o consumo e com a sociedade.

A "Sociedade em Rede" (Castells 1999) consiste no ambiente atual de intensas alterações no fluxo de informação e comunicação, alavancadas com o desenvolvimento das Tecnologias de Informação e Comunicação (TICs). Uma das características desta nova sociedade são as possibilidades advindas da comunicação móvel, sobretudo com o uso da telefonia celular. A relação da sociedade com a comunicação móvel é cada vez mais intensa porque não se trata apenas de uma questão de novas tecnologias. De acordo com Castells (2007), a comunicação móvel altera as noções de tempo e espaço, ampliando limites, comprimindo distâncias e modificando a comunicação dos indivíduos, processo fundamental para o ser humano.

Sobre este ambiente de mobilidade, Lemos (2007) reforça a criação de uma nova relação com o tempo, espaço e territórios, já que as fronteiras ficam menos delimitadas entre sujeito, identidade, espaço geográfico, cultura, política e economia.

A distância física ou geográfica, o tempo da Natureza (ligado aos fenômenos da Terra e, portanto, ao espaço) e a ausência do contato real parecem não ser mais percebidas no cotidiano. Turnos de trabalho ininterruptos nas fábricas, lojas e sistemas de entrega 24 horas, autoatendimento bancário e telefônico, internet banking, shopping centers que funcionam durante toda a madrugada. A ligação de celular que é completada e não respeita fuso horário ou localização geográfica traz a impressão de que estamos próximos, mesmo estando muito distantes.

Tudo isso parece ampliar as possibilidades e trazer mais dinamismo para a vida das pessoas, contribuindo para a mudança de hábitos, práticas sociais e 
Uma década de consumo de telefonia celular refletida na publicidade de uma marca de Silvio Koiti Sato

comportamentos. Podemos navegar pela web e estar em vários lugares simultaneamente sem sair de casa, por exemplo. Com um celular na mão, é possível estar conectado aos e-mails, enviar mensagens instantâneas, receber torpedos e checar os portais da internet, tudo ao mesmo tempo, sem sair do lugar. Isso sem falar no celular como uma central de outros dispositivos (câmera fotográfica, rádio, mp3 player, câmera de vídeo, vídeo game, etc.) que adquirem funções extras a partir de sua junção com a conectividade móvel proporcionada pela rede celular.

Portanto, a informação não depende do seu portador, é mais rápida que o corpo, que não pode mais controlar a velocidade com a qual a informação se difunde. "Dentre todos os fatores técnicos da mobilidade, um papel particularmente importante foi desempenhado pelo transporte da informação - o tipo de comunicação que não envolve o movimento de corpos físicos ou só o faz secundária ou marginalmente" (Bauman 1999: 21).

De acordo com Semprini (2006), o homem pós-moderno já foi definido como homo mobilis, com uma busca acentuada por uma necessidade de constante movimento, como se fosse uma condição para a existência humana. A telefonia móvel é citada como o grande indicador desta tendência: “A difusão extremamente rápida da telefonia móvel demonstrou que os indivíduos contemporâneos estão em movimento permanente, apesar de sentir a necessidade de manter contato com seus interlocutores, estes também em movimento." (Ibidem: 65).

A mobilidade também pode ser associada a um estilo de vida exercido de maneira mais superficial e efêmera, que se traduz no consumo de produtos e serviços com ciclos de vida cada vez menores a fim de abrir passagem para novos produtos, novas mensagens sedutoras, que também serão rapidamente substituídas, de forma volátil, instantânea, sem fim e, ao mesmo tempo, pouco satisfatórias. É uma indústria baseada não na produção de produtos e serviços, mas nas atrações.

Este ambiente de excesso (de informações, produtos, consumo e comunicação, entre outros), chamado por Lipovetsky (1989) de "Sociedade de Consumo", é caracterizado por diferentes traços como a elevação do nível de vida, a abundância de mercadorias e dos serviços, culto dos objetos e dos lazeres e a moral hedonista e materialista. É uma sociedade focada na expansão das necessidades, na obsolescência, sedução e diversificação das mercadorias. 
O processo de consumo se mostra cada vez mais intenso e instantâneo na busca dos consumidores pela satisfação de seus desejos, cada vez mais rapidamente substituídos por outros. Este processo parece ser quase sem fim, em alta velocidade, fazendo consumo e mobilidade estarem cada vez mais juntos: "o consumidor é uma pessoa em movimento e fadada a se mover sempre.” (Bauman 1999: 93)

O significado do consumo (e dos bens de consumo) vai além do valor comercial. Existe uma ampliação na habilidade em carregar e comunicar significado cultural na sociedade contemporânea. Este significado está sempre em trânsito, em movimento. "O significado esta ininterruptamente fluindo das e em direção as suas diversas localizações no mundo social, com a ajuda de esforços individuais e coletivos de designers, produtores, publicitários e consumidores" (McCracken 2003: 99).

Este é o ambiente atual das marcas, que exercem papel central na ampliação dos significados dos produtos, cada vez mais fluidos e transitórios, passando a transmitir ideias, valores e atitudes. Mais uma vez, a mobilidade se apresenta na complexidade do consumo atual, ambiente este enfrentado pelas marcas contemporâneas.

Portanto, no contexto atual, a comunicação das marcas se torna mais crítica, com desafios ao lidar com tendências de comportamento que se renovam rapidamente a cada alteração tecnológica. No caso das marcas de telefonia celular, as mudanças são constantes - o aparelho deixa de ser usado somente para ligações de voz e passa a ser utilizado para mensagens de texto (SMS), mensagens com recursos multimídia como vídeo e foto, além do acesso à Internet a partir de smartphones e tecnologias mais velozes de transmissão de dados.

Para divulgar lançamentos e novidades, a comunicação publicitária é uma ferramenta poderosa e utilizada à exaustão pelas marcas. Além do aspecto tático (específico de cada briefing e seus objetivos mercadológicos) a comunicação das marcas ambiciona fortalecer o brand equity (patrimônio de marca), sobretudo ao criar associações mais fortes com seus consumidores - neste sentido, estamos falando de relações mais próximas, de vínculos emocionais mais profundos e duradouros.

Sobre tais vínculos, Gobé (2002: 19) ressalta que no ambiente contemporâneo, marcado por excesso de ofertas de produtos e serviços e, portanto, com maior competitividade, a gestão das marcas deve atuar na criação de marcas emocionais: "Por emocional, quero dizer como uma marca se comunica com os consumidores no nível dos sentidos e das emoções". 
Verificaremos a seguir como as mudanças ocorridas no setor de telefonia móvel no Brasil são refletidas na comunicação publicitária das marcas e, além disso, como a publicidade ressalta benefícios, sensações e associações positivas relacionadas aos aspectos de mobilidade no ambiente contemporâneo a fim de criar vínculos de sentido entre consumidores e marcas.

\section{METODOLOGIA DE ANÁLISE}

Segundo Souza e Santarelli (2008: 133) "desde seu estabelecimento como ciência, a semiótica tem se utilizado da publicidade como corpus de análise." Com isso, existem estudos com peças publicitárias, sobretudo impressas, desde a década de 1950. A evolução da teoria semiótica, bem como do discurso publicitário e da gestão das marcas se reflete também no atual processo de análise das expressividades da marca com o uso da semiótica.

A semiótica peirceana foi formulada pelo americano Charles Sanders Peirce, baseada no estudo dos signos, entendendo-se, de acordo com Santaella (2002: 8) que "o signo é qualquer coisa de qualquer espécie (...) que representa uma outra coisa, chamada de objeto do signo, e que produz um efeito interpretativo em uma mente real ou potencial, efeito este que é chamado de interpretante do signo." Ela é estabelecida a partir de sucessões de trilogias, que se desdobram em combinações e classificações em três níveis. A fenomenologia peirceana é baseada em três elementos formais e universais em todos os fenômenos que surgem na mente das pessoas, chamados de primeiridade (ideias ao acaso, não conscientes, qualidades e sentimentos), secundidade (ideias de dependência, baseadas em dualidades e oposições) e terceiridade (ideia de generalidade, razão e mediação). 
Fig. 1- Tríade peirceana

(Perez, 2004: 141)

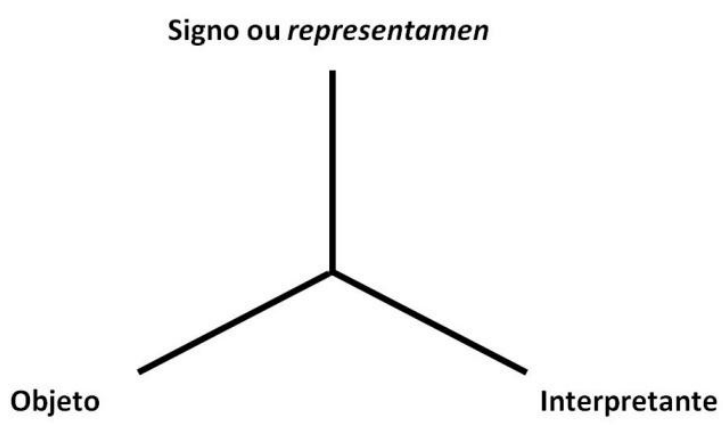

A semiótica peirceana tem como ponto central a concepção de signo: "signo é um primeiro (algo que se apresenta a mente) ligando um segundo (aquilo que o signo indica, refere ou representa) a um terceiro (o efeito que o signo provocará em uma possível mente interpretadora)" (Perez 2004: 127). Portanto, o signo tem função mediadora entre objeto e interpretante, aproximando-os e relacionando-os.

A tríade peirceana, portanto, é formada pelo signo, objeto e interpretante (Figura 1). Neste artigo, utilizaremos um modelo de avaliação de expressividades publicitárias baseado na semiótica peirceana, conforme proposto por Perez (2004). Este modelo mostra-se especialmente indicado na análise das expressividades da marca contemporânea, em que "há grande complexidade sígnica, principalmente, ao nível das expressividades. A marca reúne aspectos qualitativos, indiciais e simbólicos havendo em determinadas situações, ênfase em uma dimensão ou outra." (Perez 2007).

O processo de análise semiótica utiliza as relações triádicas do signo para sua realização, e levará em conta as tricotomias do signo em si mesmo (primeiridade) e em relação ao objeto (secundidade), avaliando as dimensões Qualitativo-Icônica, SingularIndicial e Convencional-Simbólica.

Na avaliação da dimensão Qualitativo-Icônica, levanta-se a qualidade de que é feita o signo em análise (qualissigno) e sua relação com o objeto (ícone), ou seja, os aspectos qualitativos que podem ser percebidos na primeira impressão: forma, design, cor, volume, textura, composição, linhas, luminosidade, etc. Estas qualidades mais concretas e visíveis podem dar início ao estabelecimento de relações de comparação com outros efeitos de sentido, remetendo a qualidades abstratas como, por exemplo, à força ou à delicadeza, a algo mais rústico ou elaborado. 
Uma década de consumo de telefonia celular refletida na publicidade de uma marca de Silvio Koiti Sato

Na avaliação da dimensão Singular-Indicial, a análise leva em conta o sinsigno e sua relação com o objeto (índice) a partir do entendimento de um contexto de uso e da existência do signo num determinado espaço e tempo, para um determinado uso e público. Nesta dimensão, procuram-se indícios da origem da marca, ambiente de uso, benefícios e funções do produto que a marca representa. Além disso, características do mercado em que a marca se insere também podem deixar sua marcas, identificadas nesta dimensão.

Finalmente, na avaliação da dimensão Convencional-Simbólica, a análise leva em conta a relação com o fundamento do signo e sua relação com o objeto (símbolo). Trata-se da análise do contexto cultural mais amplo no qual o produto/marca se insere não em sua singularidade, mas no seu aspecto mais universal.

Adicionalmente, a análise levará em conta teorias e conceitos específicos do discurso publicitário e dos recursos de construção de comerciais, por reconhecer que "a aplicação semiótica reclama pelo diálogo com teorias mais específicas dos processos de signos que estão sendo examinados" (Santaella 2002: 6).

\section{OBJETO DE ESTUDO}

Neste artigo, analisaremos dois comerciais publicitários da marca Vivo, líder do setor no Brasil. Dentre a extensa produção publicitária desta marca, escolhemos dois filmes que pontuam importantes momentos em sua história: o lançamento da marca e o lançamento da extensão nos serviços de convergência oferecidos pela empresa. Os dois comerciais foram veiculados com uma diferença de quase uma década (2003 e 2012), período no qual, conforme vimos, muitas alterações ocorreram no mercado de telefonia celular no Brasil. Apesar da diferença temporal, ambos possuem a mesma estrutura criativa, num formato que utiliza um jingle publicitário (a melodia é a mesma, com alterações na letra) e um clipe de imagens na parte visual (nos dois filmes, vemos cenas semelhantes, com diferenças nas técnicas de execução). Os dois filmes foram criados pela Africa Propaganda, uma das agências que atendem o anunciante.

O primeiro filme chama-se "Gesto Vivo" e foi veiculado em abril de 2003 para marcar o lançamento da marca. A Vivo substituiu sete marcas regionais utilizadas até então. Na ocasião, a nova marca foi lançada com 16 milhões de clientes, com o 
Uma década de consumo de telefonia celular refletida na publicidade de uma marca de Silvio Koiti Sato

posicionamento de ser a líder do mercado brasileiro em número de clientes e com a maior área de cobertura.

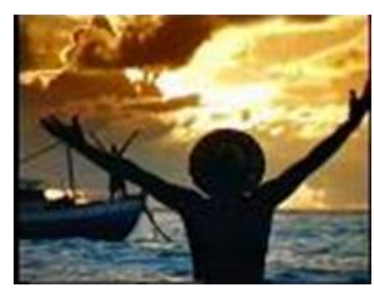

Fig. 1: Frames Comercial "Gesto Vivo",
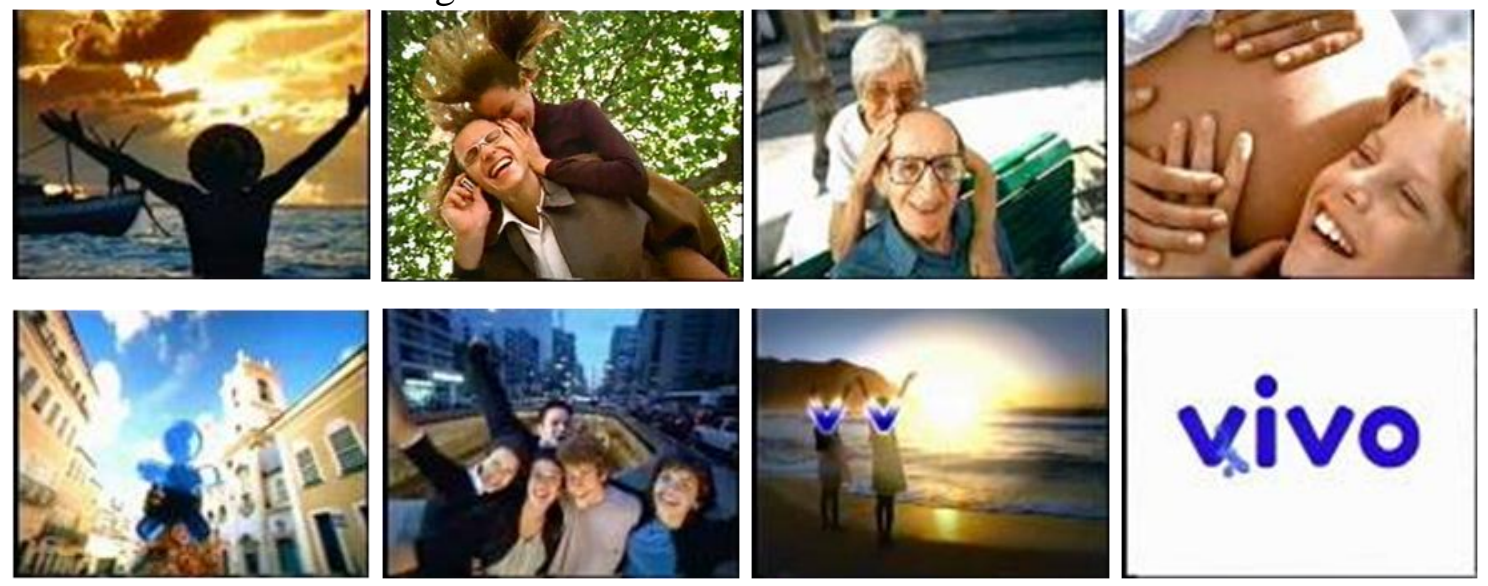

O filme utiliza a linguagem de clipe, com várias cenas em locais e com pessoas diferentes (Figura 2), com o áudio formado por uma melodia que tem a seguinte letra:

Como a lua cheia, como namorar, o canto das baleias, o barulho do mar.

(Vivo, Vivo)

Como um beija flor, como a cachoeira, o riso dos meninos, o bumbo da Mangueira.

(Vivo, Vivo)

Como a luz do sol aquecendo a vida, como um gol de placa, o grito da torcida.

(Vivo, Vivo)

Como um fim de tarde, como uma nascente, como uma canção, a gente se sente.

(Vivo, Vivo)

Como um sorriso. (Vivo) Como uma paixão. (Vivo)

Como respirar. (Vivo) O bater do coração. (Vivo)

Como uma cidade, como a pulsação, um dia, uma colmeia, como a multidão. (Vivo, Vivo)

Passaremos agora para a análise deste filme nas três dimensões do nosso percurso analítico.

\footnotetext{
${ }^{2} \mathrm{O}$ filme publicitário pode ser visualizado em: http://www.youtube.com/watch?v=rH5b7rJUxso
} 
Na dimensão Qualitativo-Icônica, a primeira impressão proporcionada pelo filme é a de um ambiente dinâmico e grandioso, com música alegre, acompanhada de imagens de diferentes grupos de pessoas, de diferentes idades e etnias, residentes em diversas regiões do Brasil. As cores são vivas, as cenas são ensolaradas, em ambientes externos, e os tons quentes predominam. A letra do jingle utiliza palavras simples e populares, que remetem à natureza ("lua cheia", "luz do sol”) e a emoções e sentimentos ( "grito da torcida", "sorriso"). As cenas também evocam a simplicidade por mostrarem situações do cotidiano do povo brasileiro, com paisagens e pessoas comuns e simples (e não modelos ou celebridades). A repetição da palavra "Vivo" (14 vezes) chama a atenção: ela encerra cada trecho da música na forma de um coro de vozes com muito destaque e ritmo.

Na dimensão Singular-Indicial, o contexto de uso do produto ou serviço anunciado, no caso a telefonia celular, não é explicitado pela letra da música. Entretanto, existem palavras que evocam a interatividade entre as pessoas ("o riso dos meninos", “como a multidão"), e que reforçam o sentido de "comunidade", remetendo a pessoas unidas e aglomeradas num mesmo espaço. As poucas cenas de uso do celular são discretas e naturais. A diversidade de pessoas que aparecem no comercial indica que toda a população (todos os seres "vivos") está incluída nesta mensagem e é alvo do anunciante. Além disso, o uso de palavras e cenas que remetem a ambientes externos ("cachoeira", "barulho do mar") remete também à mobilidade proporcionada pela telefonia celular e a mensagem de que este serviço funciona em todos os lugares. A repetição da palavra "Vivo" e a ênfase no arranjo e na interpretação cada vez em que ela é cantada têm o objetivo de fixar a palavra (o nome da nova marca) e associá-la ao espírito e às emoções transmitidas pelas cenas e pela música do comercial.

$\mathrm{Na}$ análise Convencional-Simbólica, o conjunto de imagens, palavras, ritmo e expressões tem o potencial de transmitir a ideia de um país otimista e feliz, com valores familiares e espírito puro. Nesse sentido, ocorre uma representação idealizada do povo brasileiro. Existe semelhança com o discurso de campanhas governamentais ou políticopartidárias, ao tentar criar uma identidade brasileira a partir de certas características como o futebol e o Carnaval, por exemplo. As cenas podem provocar identificação por parte de qualquer brasileiro, seja pela diversidade dos tipos físicos e paisagens regionais ou pelas expressões esportivas e culturais. A expressão corporal das pessoas do comercial transmite receptividade à nova marca: vemos pessoas erguendo os braços, 
Uma década de consumo de telefonia celular refletida na publicidade de uma marca de Silvio Koiti Sato

num gesto típico de "boas-vindas". No final do comercial, este gesto se funde com o formato das duas letras "V" do logotipo "Vivo". A música também reforça o efeito de "acolhida" do brasileiro à nova marca: a divisão entre voz principal feminina e o coro simula o diálogo entre a marca (voz feminina) e a população (coro). O coro parece chamar e clamar pela marca ao cantar "Vivo".

O segundo comercial (“Conectados vivemos melhor”) foi veiculado em março de 2012. Ele comunica a evolução da marca para além dos serviços de telefonia móvel, ao oferecer telefonia fixa, internet banda larga e televisão a cabo. Nesse momento, a empresa possui 76 milhões de clientes nesse momento (dados de julho/2012 - fonte: Teleco). Este filme também utiliza a linguagem de clipe de imagens. Entretanto, dessa vez, usa a animação no lugar de cenas filmadas com pessoas e locais reais (Figura 3).

Figura 3: Frames Comercial "Conectados vivemos melhor"3

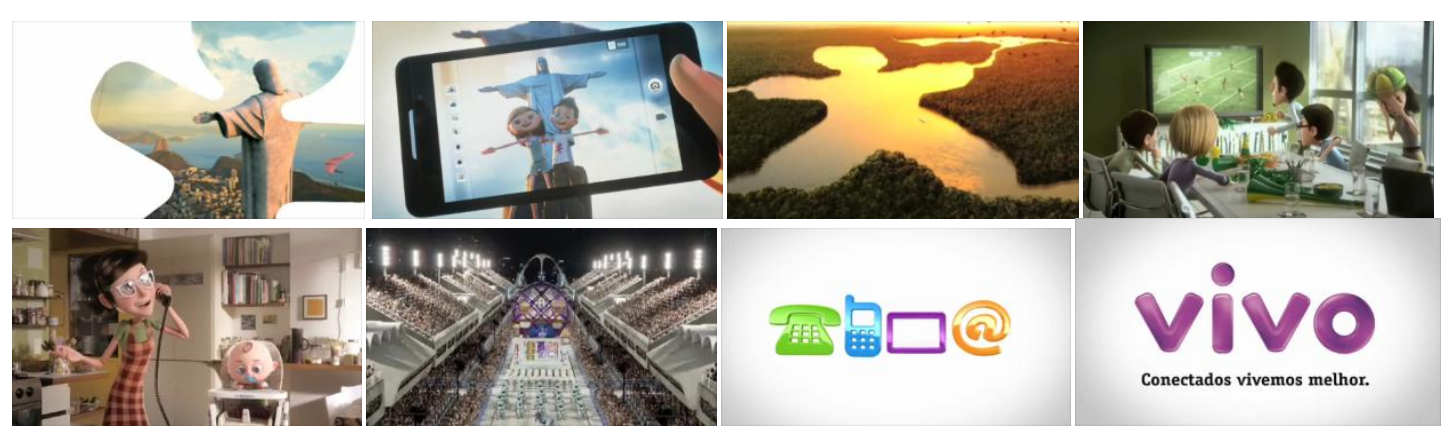

A melodia deste comercial é a mesma do primeiro filme analisado, mas recebe uma nova letra, mais adequada à nova mensagem a ser comunicada:

Conecte-se com a vida, com a emoção, com a alegria, o sonho e a razão.

(Vivo, Vivo)

No telefone fixo ou no celular, conectado sempre e em qualquer lugar.

(Vivo, Vivo)

Pra chegar mais longe, pra estar do lado, pra viver melhor, Vivo conectado.

(Vivo, Vivo)

No computador, na TV a cabo, no tablet também, tudo conectado.

(Vivo, Vivo)

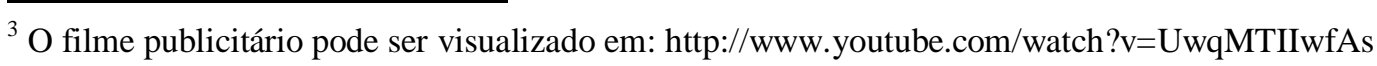


Uma década de consumo de telefonia celular refletida na publicidade de uma marca de Silvio Koiti Sato

Agora a Vivo é celular, fixo, internet e TV. Você tem mais conexões e suas conexões mais qualidade, pra você viver cada vez melhor.

O que quiser sonhar, o que quiser fazer, Conexão é Vivo, o mundo pra você.

Vivo. Conectados vivemos melhor.

Realizaremos a avaliação deste segundo filme seguindo novamente as três dimensões do nosso percurso analítico.

Na dimensão Qualitativo-Icônica, a primeira impressão proporcionada pelo filme é a de um ambiente mágico e colorido proporcionado pela estética do desenho animado, que nos remete a um ambiente mais lúdico, de entretenimento e, de certa maneira, infantil e ingênuo. As personagens representam pessoas de diferentes idades, etnias e grupos sociais. Elas portam e interagem com celulares, computadores, telefones fixos e tablets. Estão em suas residências, meios de transporte urbanos e em localidades no Brasil e no exterior, mesclando espaços abertos e fechados, cenas rurais e em cenários da metrópole. Dentre os locais retratados, temos espaços de grande concentração de pessoas, como estádios e desfiles de Carnaval. O traço do desenho é arredondado, não agressivo, com uso de paleta de cores fortes e quentes. Os movimentos de câmera e a edição são dinâmicos, bem como a letra e ritmo do jingle, que também trazem a sensação do movimento e rapidez. Palavras do universo da tecnologia ("conexão", "tablet”) são combinadas a outras mais emocionais ("sonho", "vida"), de uma forma equilibrada. Da mesma maneira, voz feminina (jingle) e masculina (locução) são joviais e descontraídas, e também se complementam.

Na dimensão Singular-Indicial, os serviços oferecidos pela marca são mostrados de forma explícita no comercial: os novos serviços oferecidos (telefonia e internet fixas, e TV a cabo), são apresentados repetidamente nas cenas, no jingle, na locução e em pictogramas no final do comercial. A área de cobertura do serviço é sugerida em cenas externas, nas quais a silhueta da mascote da marca (o boneco Vivo) indica a qualidade da ligação em locais distantes e no exterior. A marca também pretende comunicar a abrangência do seu público-alvo ao representar pessoas de diferentes tipos físicos, etnias, idades e localidades. Destacamos a presença de um deficiente físico na cena do metrô e a cena em que Pelé e Maradona são representados numa expressão de amizade e harmonia. Finalmente, a execução visual, com uso da linguagem de animação aos 
Uma década de consumo de telefonia celular refletida na publicidade de uma marca

moldes da produtora americana Pixar, remete a um universo de alta tecnologia e inovação, adequado ao setor de atuação da marca.

$\mathrm{Na}$ análise Convencional-Simbólica, o comercial apresenta uma visão otimista das possibilidades trazidas pela conexão na vida das pessoas e nas suas relações sociais. O uso dos serviços da marca é quase sempre apresentado de forma coletiva, em meio a outras pessoas. A incorporação dos recursos de conexão no cotidiano é mesclada com interações no ambiente físico, apresentadas de forma harmônica e complementar. Temos também uma simbologia que une o local e o global de forma equilibrada, expressa de várias maneiras: o recurso do desenho animado diminui a associação com o ponto de vista local e específico brasileiro, universalizando a mensagem para um imaginário mais amplo, aderente ao deslocamento espaço-temporal proporcionado pela comunicação móvel. A linguagem do desenho animado, entretanto, é amenizada pela caracterização dos personagens, locações retratadas (pontos turísticos brasileiros como o Cristo Redentor) e pelo ritmo da música, o samba. O packshot do comercial é formado por pictogramas que representam os serviços oferecidos pela marca e pelo logotipo. Os elementos apresentam tratamento visual com volume e sombra, o que convida ao toque e remete à estética dos ícones dos computadores e dos celulares touchscreen. Eles estão posicionados em fundos infinitos brancos, sem localização definida: é uma expressão do não-espaço, recorrente em representações publicitárias de tecnologia. O movimento constante é valorizado pelo ritmo, cenas e edição de imagens do comercial. Esta sensação parece coerente com o estilo de vida mais intenso e rápido no qual estamos inseridos hoje. Finalmente, o gesto de "boas-vindas", com os braços abertos, é utilizado também neste comercial, e tem potencial de transmitir receptividade à tecnologia trazida marca na forma dos novos serviços comunicados.

\section{CONSIDERAÇÕES FINAIS}

A análise dos filmes publicitários mostra a grande diferença situacional em que cada um deles foi criado e divulgado.

O primeiro comercial (“Gesto Vivo"), de 2003, lança a marca e apresenta a telefonia celular ainda como uma novidade chegando para todos os brasileiros, com mensagens claras sobre a expansão do serviço e sua popularização, num contexto em que a telefonia de uma maneira geral, inclusive as linhas fixas, atendia a uma pequena parcela da população, residente em zonas urbanas e com maior poder aquisitivo. A 
Uma década de consumo de telefonia celular refletida na publicidade de uma marca

marca é lançada com um caráter nacional, ligado ao país e a todos que nele residem, com uma perspectiva inclusiva e abrangente, reforçada pela repetição insistente da marca Vivo, o que reflete seu caráter inaugural. O objetivo era apresentar a Vivo como uma nova empresa que estava intimamente ligada ao Brasil, com o intuito principal de gerar conhecimento e curiosidade sobre a telefonia celular, ainda pouco difundida na época. O comercial reflete este momento do mercado da telefonia móvel, que ainda possuía grande demanda reprimida, sobretudo nas classes mais populares, o que suscita uma associação entre o tom de discurso público (propaganda do governo) do comercial e a posterior "democratização" da comunicação móvel que de fato ocorreu no país nos anos seguintes.

Já o segundo filme (“Conectados vivemos melhor”), de 2012, apresenta a evolução no posicionamento da marca, quase uma década depois do lançamento da marca, num momento em que a telefonia celular já é um serviço corriqueiro, no cotidiano de pessoas das mais variadas classes e faixas etárias. O celular não se restringe mais somente ao uso para ligações de voz, é utilizado para conectar-se por mensagens de texto, vídeo e Internet. Além disso, o filme insere repetidamente os novos serviços da marca, em situações de uso que destacam a recorrência da conectividade no cotidiano atual. A linguagem de desenho animado atualiza a execução do comercial, ao inserir personagens animados que substituem pessoas reais e filmagens em locações, refletindo a virtualidade do ambiente contemporâneo. A abordagem, embora informativa e persuasiva para promover os novos serviços, tenta equilibrar este aspecto com um foco também emocional, utilizando humor e trazendo um aspecto mais lúdico na própria linguagem do desenho animado. A brasilidade também parece equilibrada a uma visão maior de mundo, unindo o local ao global. A nova assinatura ("Conectados vivemos melhor") resume a visão otimista da marca, condizente com seus objetivos de negócios, pois associa aspectos positivos do ambiente no qual está inserida (sociedade em rede) com seus objetivos mercadológicos, mostrando coerência entre suas crenças e seus interesses.

Por meio da análise semiótica desses dois filmes publicitários, pudemos perceber que o cenário competitivo da categoria, seus desdobramentos no comportamento de uso e consequências nas práticas sociais são refletidas nas mensagens publicitárias, sendo utilizadas para persuadir e gerar maior adequação da mensagem ao contexto do usuário e, adicionalmente, reforçar os vínculos com a marca. Fica evidente que ao mesmo 
Uma década de consumo de telefonia celular refletida na publicidade de uma marca de Silvio Koiti Sato

tempo em que a publicidade reflete os valores sociais, ela também influencia esses mesmos valores, estimulando um estilo de vida conectado, característico do cotidiano atual.

\section{REFERÊNCIAS BIBLIOGRÁFICAS}

AAKER, D. A. Marcas, Brand Equity: Gerenciando o valor da marca. São Paulo, Elsevier Editora, 1998.

ANDERSON, Chris. Free: grátis: o futuro dos preços. Rio de Janeiro, Elsevier, 2009.

BAUMAN, Z. Globalização: as conseqüências humanas. Rio de Janeiro, Jorge Zahar Ed., 1999.

CASTELLS, M. A Sociedade em Rede. São Paulo, Paz e Terra, 1999.

; FERNÁNDEZ-ARDÈVOL, M.; QIU, J. L.; SEY, A. Mobile Communication and Society: a global perspective. Cambridge, MIT Press, 2007

DI NALlO, E. Meeting Points: Soluções de Marketing para uma Sociedade Complexa. São Paulo, Marcos Cobra, 1999.

GIDDENS, A. As conseqüências da modernidade. São Paulo, Unesp, 1991.

GOBÉ, M. A emoção das marcas. Rio de Janeiro, Campus, 2002.

KAPFERER, J. N. As marcas, capital da empresa: criar e desenvolver marcas fortes. Porto Alegre, Bookman, 2003.

. O que vai mudar as marcas. Porto Alegre, Bookman, 2006.

KLEIN, N. Sem logo: a tirania das marcas em um planeta vendido. Rio de Janeiro, Record, 2004.

LEMOS, A. Cidade e mobilidade: telefones celulares, funções pós-massivas e territórios informacionais. In: Revista Matrizes-ECA/USP, no.1, São Paulo, outubro 2007.

LIPOVETSKY, G. O império do efêmero: a moda e seu destino nas sociedades modernas. São Paulo, Companhia das Letras, 1989.

MCCRACKEN, G. Cultura e consumo: novas abordagens ao caráter simbólico dos bens e das atividades de consumo. Rio de Janeiro, MAUAD, 2003.

PEREZ, C. Signos da Marca: Expressividade e Sensorialidade. São Paulo, Pioneira Thomson Learning, 2004. 
Uma década de consumo de telefonia celular refletida na publicidade de uma marca

Gestão e Semiótica da Marca: a Publicidade como Construção e Sustentação Signica. In: INTERCOM - Anais do XXX Congresso Brasileiro de Ciências da Comunicação, Santos, 2007.

SANTAELLA, L. Semiótica aplicada. São Paulo, Pioneira Thomson Learning, 2002. - A ecologia pluralista das mídias locativas. In: Dossiê ABCiber. Revista FAMECOS - Porto Alegre - no. 37 - dezembro de 2008. ; NOTH, W. Estratégias semióticas da publicidade. São Paulo, Cengage Learning, 2010.

SATO, S. K. Construção de marca em telefonia móvel no Brasil - contribuições da análise semiótica aplicada à publicidade. In: XXXII Congresso Brasileiro de Ciências da Comunicacao, 2009 - Intercom 2009. Positivo: Curitiba, 2009. v.1. p.1261-1276.

SEMPRINI, A. A marca pós-moderna: poder e fragilidade da marca na sociedade contemporânea. São Paulo, Estação das Letras Editora, 2006.

SOUZA, S. M. R.; SANTARELLI, C. P. G. Contribuições para uma história da análise da imagem no anúncio publicitário. In: Intercom - Revista Brasileira de Ciências da Comunicação, v.31, n.I, São Paulo, jan./jun. 2008, p.133-156.

TRINDADE, E. A publicidade e a modernidade-mundo. As representações de pessoa, espaço e tempo. In: BARBOSA, I.S. (org.) Os sentidos da publicidade. Estudos Interdisciplinares. São Paulo: Thomson Learning, 2005. p. 81-96

WILliAMS, R. Palavras-chave: um vocabulário de cultura e sociedade. São Paulo, Boitempo, 2007.

Artigo submetido: dezembro de 2012

Artigo aprovado: dezembro de 2012 